Bangladesh Pharmaceutical Journal 25(1): 54-66, 2022 (January)

\title{
A Cross-sectional Study on Breast Cancer among the Bangladeshi Female Population
}

\author{
Faria Nasrin ${ }^{1}$, Muhammad Rashedul Islam² and Md. Elias-Al-Mamun ${ }^{2}$ \\ ${ }^{1}$ Department of Pharmacy, Faculty of Pharmacy, University of Dhaka, Dhaka-1000 Bangladesh \\ ${ }^{2}$ Department of Pharmaceutical Technology, Faculty of Pharmacy, University of Dhaka Dhaka-1000, \\ Bangladesh
}

(Received: December 13, 2021; Accepted: January 22, 2022; Published (web): January 29, 2022)

\begin{abstract}
The goal of the study was to analyze Bangladeshi women's knowledge of breast cancer and attitudes toward breast self-examination (BSE) practice along with the participants' trust in the breast cancer treatment facility in Bangladesh. The cross-sectional study was carried out between March and July of 2021 among 268 Bangladeshi women over the age of 15 through Google form-based questionnaire who were asked 18 questions about breast cancer. The acquired data were analyzed using SPSS version 25 and Excel. The $88 \%$ of those surveyed had heard of breast cancer, and $63.4 \%$ were aware of its symptoms. Participants' overall knowledge of breast cancer was not satisfactory, with a mean knowledge score of 3.53 on a scale of 0 to 6, and $40.3 \%$ fell into the "good knowledge" category. Age, education, residence, and a family history of breast cancer were significant predictors of knowledge level. Only $53 \%$ had heard of BSE before, and only $29.5 \%$ admitted to being familiar with the BSE technique. Only $23.5 \%$ had previously conducted BSE. Only $11.2 \%$ of those polled had faith in Bangladesh's breast cancer treatment facilities. Based on the findings of this study, it can be assumed that the majority of women in Bangladesh have minimal understanding of breast cancer, the most common cancer among Bangladeshi women. It is high time to take the required steps to raise awareness about breast cancer and BSE. Furthermore, widespread access to mammograms, radiation, and oncology treatment should be ensured in an attempt to restore faith in healthcare facilities.
\end{abstract}

Key words: Breast cancer, Breast self-examination (BSE), Knowledge, Practice, Barrier, Confidence

\section{Introduction}

Breast cancer is the most common cancer in the world. In 2020, around 2.3 million women were diagnosed with breast cancer. Breast cancer accounts for one in every four cancer cases in women (Sung et al., 2021). According to Global Cancer Statistics 2012, less developed nations detected more than half (56.8\%) of all cancer cases (Torre et al., 2015). As a result, cancer has arisen as a significant public health issue in both developed and less developed countries.

According to the WHO population fact sheet report, breast cancer is the most frequent type of cancer among women in Bangladesh, accounting for $19 \%$ of new cancer cases in 2020. Breast cancer is becoming more common due to lifestyle changes and higher life expectancy (Lam et al., 2008). While more than $70 \%$ of breast cancer patients in highincome countries are diagnosed in stages I and II, only $20 \%$ to $50 \%$ of those in low and middle-income countries are diagnosed earlier (Unger-Saldaña, 2014). When breast cancer is found early, there is a greater chance of survival and more successful treatment ( $\mathrm{Lu}$ et al., 2008). Appropriate understanding and awareness of breast cancer among women can be critical for early detection and management of their condition.

According to the American Cancer Society mammography is the most reliable tool for detecting 
breast cancer early. They suggest starting mammograms at 45 and continuing them annually for ages between 45 and 54 (Oeffinger et al., 2015). However, this procedure is economically unfeasible for most developing-country women, such as those in Bangladesh, and widespread access to mammograms is limited here. Although some studies have indicated that BSE causes a lot of false-positive diagnoses and undue worry in patients, it can be a useful tool for detecting any breast anomaly in a resourceconstrained nation like Bangladesh, prompting physician visits for a more conclusive diagnosis. In addition, a study conducted among women discovered that BSE has a sensitivity of $71-78 \%$ and is efficient in detecting breast lesions (Lam et al., 2008). Furthermore, the sensitivity of mammography is found to decrease in younger people (Rosenberg et al., 1998). So, mammograms should not be regarded as the "gold standard" for detecting breast cancer, and women aged 20 to 40 can accept a monthly BSE as part of breast cancer awareness.

The quality of a country's healthcare system is measured by how satisfied its patients are. Bangladesh, being a resource-constrained and heavily populated country, has yet to reach optimal patient satisfaction. A 2016 study provided a bleak picture of patients' trust in Bangladesh's current treatment facilities, with $90.5 \%$ of respondents preferring to seek overseas medical services (Kumar et al., 2021). Because no previous research has explored whether women in Bangladesh trust the treatment they receive for breast cancer, this is the ideal time to find out.

This cross-sectional study was conducted to evaluate the understanding and perception of breast cancer among the female population of Bangladesh and their confidence in Bangladesh's breast cancer management strategy. Men of Bangladesh were phased out from this study as they are at lower risk than their counterparts, contributing only $0.5 \%-1 \%$ of total breast cancer cases (Yalaza et al., 2016).

\section{Materials and Methods}

Study design: A cross-sectional study was conducted from March 2021 to July 2021 among the female population of Bangladesh to evaluate their perception regarding breast cancer and BSE and their confidence regarding breast cancer treatment facilities in Bangladesh. Bangladeshi women above 15 years of age were eligible to take part in the study. This study enrolled a total of 268 females.

Data collection: A Google form questionnaire was developed after going through several survey articles about breast cancer. The questionnaire comprised six sections and 18 questions. Questions were translated both in Bengali and English for the convenience of the participants. The questionnaire was pretested on a randomly selected sample of 20 women. Finally, data were collected via a revised, self-administered questionnaire circulated through a Google form.

Measure: The first section of the questionnaire gathered data about demographic factors like age, marital status, education, occupation, residence, and family history of breast cancer. In the second part, knowledge about breast cancer and BSE was evaluated by asking six close-ended questions. Options for the questions included yes or no and agree or disagree. The third part assessed the practice tendency and frequency of BSE by asking two closeended questions. The fourth section assessed the barriers to BSE practice. The fifth portion studied access to information about breast cancer and BSE, while the last section explored attitudes toward breast cancer treatment facilities in Bangladesh.

Analysis: Data were processed using IBM Statistical Package for Social Science (SPSS) version 25 and Microsoft Excel. All categorical data were analyzed using descriptive statistics (frequency and percentage). Pearson chi-square test was employed to assess the relationship between categorical variables, and multinomial logistic regression was used to determine the significant predictor variables of a dependent variable. The level of statistical significance was set to $\mathrm{p}<0.05$. 
Survey Form

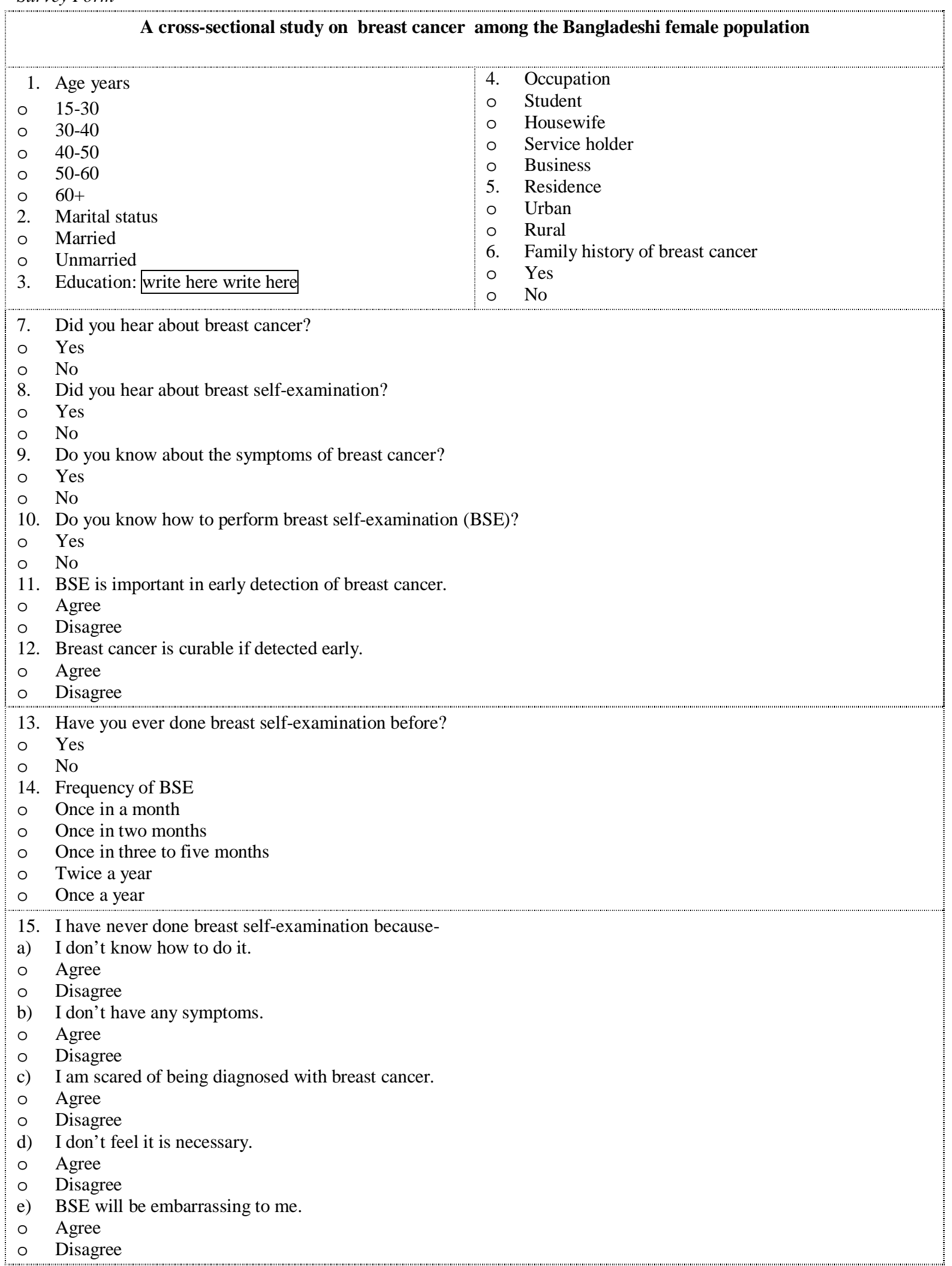




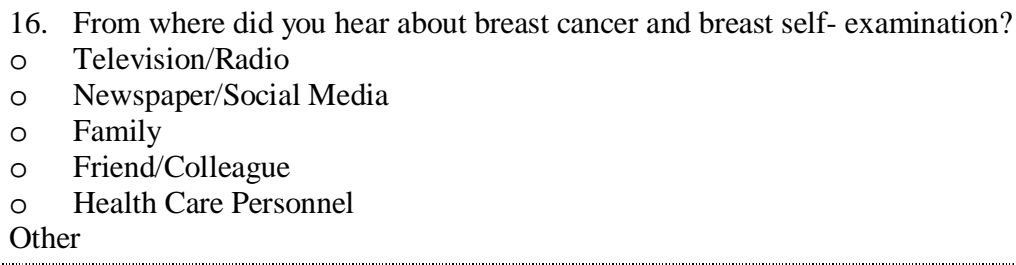

18. If you don't have confidence in the breast cancer treatment facility in Bangladesh, then which country do you prefer? Write here write here write here

\section{Results and Discussion}

Socio-demographic distribution of study participants: The socio-demographic characteristics of 268 respondents are presented in Table 1. The majority of the participants were in 15-30 years of age $(56.3 \%)$, married (57.5\%), had attended university (41.4\%). More than half of the participants were residents of urban areas $(68.3 \%)$. About $18.3 \%$ of the participants had a positive family history of breast cancer. The majority of the participants were students $(42.5 \%)$ by profession, followed by housewives $(38.4 \%)$, service holders $(13.8 \%)$, and businesses $(5.2 \%)$.

Table 1. Socio-demographic characteristics of participants $(\mathrm{N}=268)$.

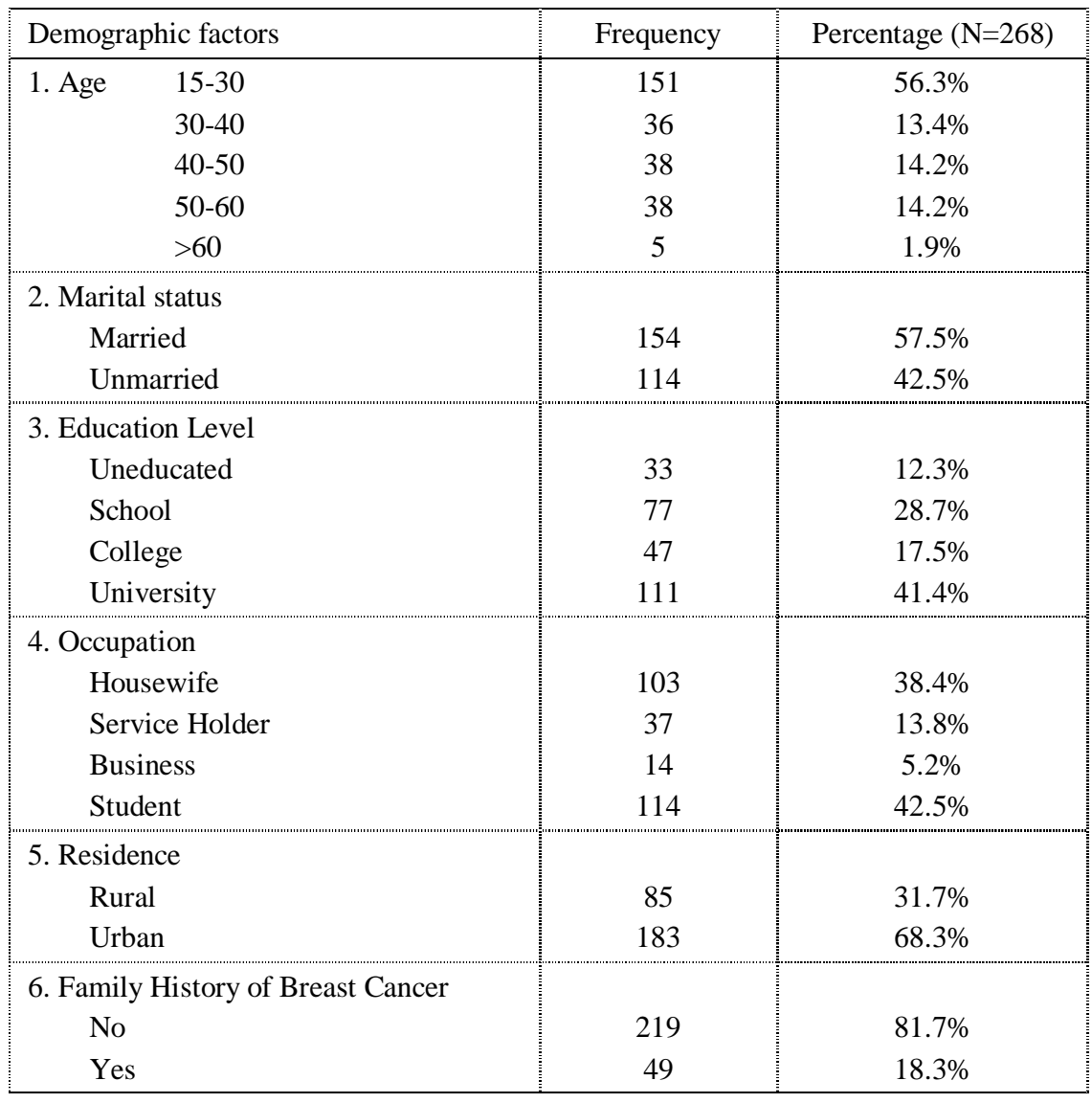


4.2 Knowledge of breast cancer and breast selfexamination (BSE)

Six close-ended questions with yes/no and agree/disagree responses were used to measure participants' knowledge of breast cancer and BSE as shown in Table 02 and Figure 01. The majority of the participants had heard about breast cancer (87.7\%),
BSE (53\%), and said they were familiar with breast cancer symptoms (63.4\%). However, more than twothirds of the respondents didn't know how to perform BSE. On the other hand, around half of the participants agreed on the importance of BSE in the early diagnosis of breast cancer and $68.3 \%$ agreed on the curability of breast cancer if identified early.

Table 2. Knowledge on breast cancer and BSE.

\begin{tabular}{llcc}
\hline Knowledge on breast cancer and BSE & Yes $(\%)$ & No $(\%)$ \\
\hline 1. & Did you hear about breast cancer? & $235(87.7 \%)$ & $33(12.3 \%)$ \\
2. Did you hear about BSE? & $142(53.0 \%)$ & $126(47.0 \%)$ \\
3. Do you know about the symptoms of breast cancer? & $170(63.4 \%)$ & $98(36.6 \%)$ \\
4. Do you know how to perform BSE? & $79(29.5 \%)$ & $189(70.5 \%)$ \\
5. $\quad$ BSE is important in early detection of breast cancer. & $138(51.5 \%)$ & $130(48.5 \%)$ \\
6. $\quad$ Breast cancer is curable if detected early. & $183(68.3 \%)$ & $85(31.7 \%)$ \\
\hline
\end{tabular}

A knowledge scale was developed using these questions. Each correct response received a single point, while each incorrect answer received 0 credits. A knowledge scale ranging from 0 to 6 was established in this manner. A knowledge score of 0-2 was regarded as "low knowledge," 3-4 as "moderate knowledge," and 5-6 as "good knowledge." The mean score of the participants was 3.53 , with a standard deviation of 2.115. Less than half of the participants had good knowledge regarding breast cancer and BSE (40.3\%), followed by poor knowledge (34\%) and moderate knowledge (25.7\%) (Figure 02).

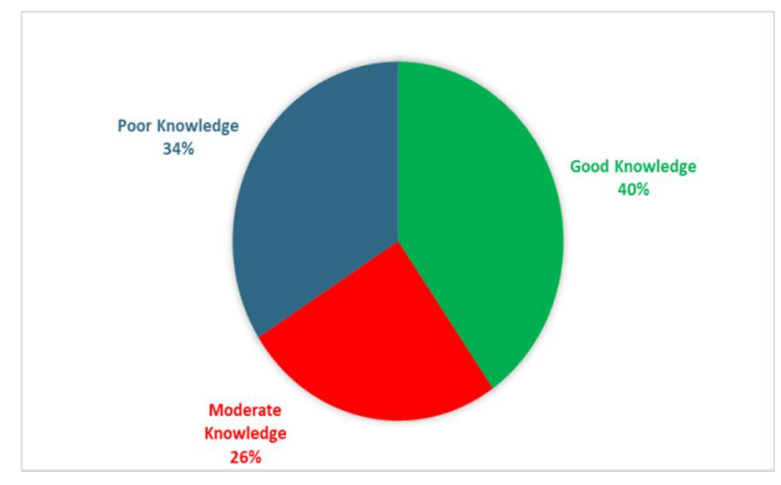

Figure 1. Knowledge level of participants regarding breast cancer and BSE.
A chi-square test was used to assess the association between socio-demographic factors and knowledge levels (Table 03). All socio-demographic characteristics and knowledge levels were found to have a significant relationship $(\mathrm{P}<0.05)$.

Multinomial logistic regression was used to identify which independent variables (sociodemographic traits) significantly predicted the participants' knowledge level (Table 03). Here "good knowledge" was considered as the reference category. Educational status, residence, and family history were significant and discriminating predictors in the comparison between good and poor knowledge. Participants with greater education $(\mathrm{B}=-$ 3.134, $\mathrm{SE}=0.425, \mathrm{P}=0.000$ ) had a lower risk of having insufficient knowledge of breast cancer and diagnosis procedures than those with less education $(\mathrm{B}=-3.134, \mathrm{SE}=0.425, \mathrm{P}=0.000)$. Furthermore, participants in urban regions were less likely to have a weak understanding than those in rural areas $(\mathrm{B}=$ $2.752, \mathrm{SE}=0.630, \mathrm{P}=0.000$ ). Positive family history of breast cancer reduced the risk of having poor knowledge compared to negative history $(\mathrm{B}=-2.705$, $\mathrm{SE}=0.740, \mathrm{P}=0.000$ ). 
In comparison between good and moderate knowledge, age, educational level, and residence were significant predictors. With age, the likelihood of having intermediate knowledge was observed to increase $(\mathrm{B}=9.718, \mathrm{SE}=0.342, \mathrm{P}=0.036)$. Higher educational levels lowered the risk of having moderate knowledge $(\mathrm{B}=-1.497, \quad \mathrm{SE}=0.297$, $\mathrm{P}=0.000$ ). However, participants residing in urban areas were less likely to have moderate knowledge than those in rural areas $(B=-1.052, S E=0.505$ $\mathrm{P}=0.037$ ).

Table 3. Association between sociodemographic characteristics and knowledge level of the respondents.

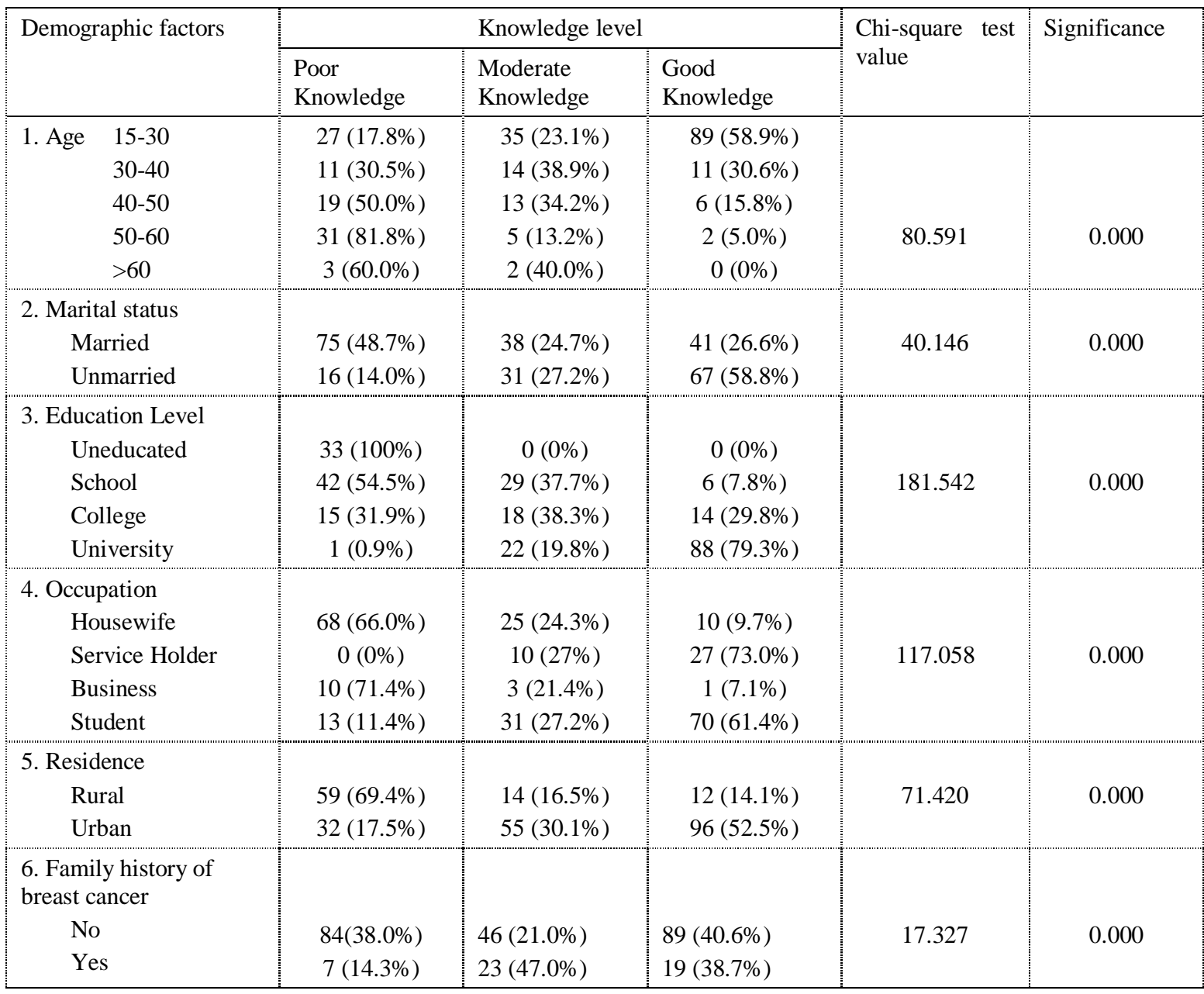

Practice of BSE: Less than a quarter of the participants had performed BSE before (23.5\%). Among them, $5.2 \%$ did it once every month, $3 \%$ did it once in every two months, $7.5 \%$ did it once in every three to five months, $4.5 \%$ twice in a year, and $5.2 \%$ once in a year (Figure 2 ).

In addition, a statistically significant link existed between BSE practice and age, marital status, educational level, occupation, and residence $(\mathrm{p}<0.05)$ (Table 5).

In terms of the practice tendency of BSE, there was a statistically significant difference between different knowledge levels (X2=115.660, $\mathrm{P}=0.000)$. Participants with a poor understanding of breast cancer had never done a breast self-examination, while $57.4 \%$ of those with a high understanding had done one before. 
Table 4. Multinomial logistic regression to predict the influence of socio-demographic characteristics on the knowledge level.

\begin{tabular}{|c|c|c|c|c|c|c|c|c|}
\hline \multirow{2}{*}{\multicolumn{2}{|c|}{ Knowledge Level }} & \multirow[t]{2}{*}{ B } & \multirow[t]{2}{*}{ Std. error } & \multirow[t]{2}{*}{ Wald } & \multirow[t]{2}{*}{ Sig. } & \multirow[t]{2}{*}{$\operatorname{Exp}(B)$} & \multicolumn{2}{|c|}{$\begin{array}{l}\text { 95\% Confidence Interval for } \\
\operatorname{Exp}(\mathrm{B})\end{array}$} \\
\hline & & & & & & & Lower bound & Upper bound \\
\hline \multirow{7}{*}{$\begin{array}{l}\text { Poor } \\
\text { Knowledge }\end{array}$} & Intercept & 8.439 & 1.462 & 33.321 & 0.000 & & & \\
\hline & 1. Age & 0.791 & 0.389 & 4.123 & 0.042 & 2.205 & 1.028 & 4.729 \\
\hline & 2. Marital status & -0.687 & 0.965 & 0.506 & 0.477 & 0.503 & 0.076 & 3.338 \\
\hline & 3. Educational level & -3.134 & 0.425 & 54.483 & 0.000 & 0.044 & 0.019 & 0.100 \\
\hline & 4. Occupation & -0.290 & 0.344 & 0.708 & 0.400 & 0.749 & 0.381 & 1.469 \\
\hline & 5. Residence & -2.752 & 0.630 & 19.117 & 0.000 & 0.064 & 0.019 & 0.219 \\
\hline & $\begin{array}{l}\text { 6. Family history of } \\
\text { breast cancer }\end{array}$ & -2.705 & 0.740 & 13.360 & 0.000 & 0.067 & 0.016 & 0.285 \\
\hline \multirow{7}{*}{$\begin{array}{l}\text { Moderate } \\
\text { Knowledge }\end{array}$} & Intercept & 4.304 & 1.171 & 13.512 & 0.000 & & & \\
\hline & 1. Age & 0.718 & 0.342 & 4.412 & 0.036 & 2.051 & 1.049 & 4.009 \\
\hline & 2. Marital status & -0.720 & 0.657 & 1.202 & 0.273 & 0.487 & 0.134 & 1.763 \\
\hline & 3. Educational level & -1.497 & 0.297 & 25.445 & 0.000 & 0.224 & 0.125 & 0.400 \\
\hline & 4. Occupation & -0.121 & 0.259 & 0.218 & 0.641 & 0.886 & 0.534 & 1.472 \\
\hline & 5. Residence & -1.052 & 0.505 & 4.344 & 0.037 & 0.349 & 0.130 & 0.939 \\
\hline & $\begin{array}{l}\text { 6. Family history of } \\
\text { breast cancer }\end{array}$ & -0.353 & 0.529 & 0.444 & 0.505 & 0.703 & 0.249 & 1.982 \\
\hline
\end{tabular}

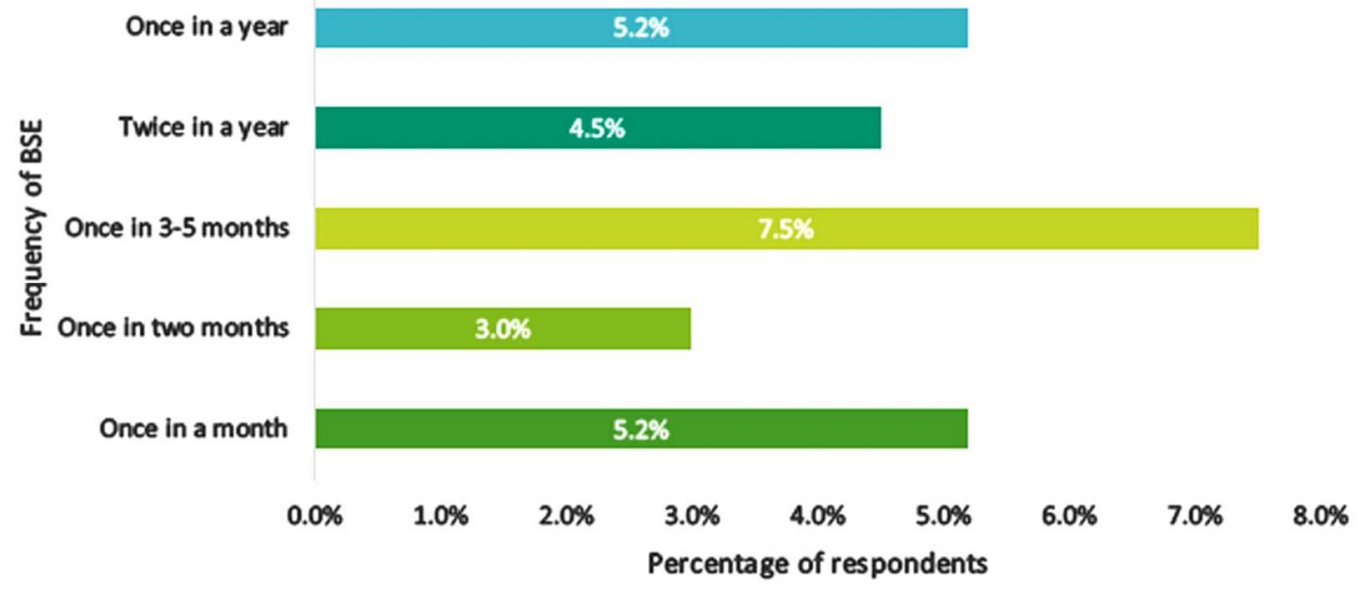

Figure 2. Frequency of BSE practice. 
Table 5. Factors associated with practice tendency of BSE.

\begin{tabular}{|c|c|c|c|c|c|}
\hline \multirow{2}{*}{\multicolumn{2}{|c|}{ Demographic factors }} & \multicolumn{2}{|c|}{ Have you ever done BSE before? } & \multirow{2}{*}{$\begin{array}{l}\text { Chi square } \\
\text { test }\end{array}$} & \multirow[t]{2}{*}{ significance } \\
\hline & & No $(\%)$ & Yes $(\%)$ & & \\
\hline \multicolumn{6}{|c|}{ 1. Age $15-30$} \\
\hline & $30-40$ & $100(66.2 \%)$ & $51(33.8 \%)$ & 21.921 & 0.000 \\
\hline & $40-50$ & $30(83.3 \%)$ & $6(16.7 \%)$ & & \\
\hline & $50-60$ & $34(89.5 \%)$ & $4(10.5 \%)$ & & \\
\hline \multirow{2}{*}{\multicolumn{2}{|c|}{$>60$}} & $36(94.7 \%)$ & $2(5.3 \%)$ & & \\
\hline & & $5(100 \%)$ & $0(0 \%)$ & & \\
\hline \multicolumn{6}{|c|}{ 2.Marital status } \\
\hline \multicolumn{2}{|c|}{ Married } & $127(82.5 \%)$ & $27(17.5 \%)$ & 7.188 & 0.007 \\
\hline \multicolumn{2}{|c|}{ Unmarried } & $78(68.4 \%)$ & $36(31.6 \%)$ & & \\
\hline \multicolumn{6}{|c|}{ 3.Education Level } \\
\hline \multicolumn{2}{|c|}{ Uneducated } & $33(100 \%)$ & $0(0 \%)$ & 45.258 & 0.000 \\
\hline \multicolumn{2}{|c|}{ School } & $71(92.2 \%)$ & $6(7.8 \%)$ & & \\
\hline \multicolumn{2}{|c|}{ College } & $38(80.9 \%)$ & $9(19.1 \%)$ & & \\
\hline \multicolumn{2}{|c|}{ University } & $63(56.8 \%)$ & $48(43.2 \%)$ & & \\
\hline \multicolumn{6}{|c|}{ 4.Occupation } \\
\hline \multicolumn{2}{|c|}{ Housewife } & $96(93.2 \%)$ & $7(6.8 \%)$ & 43.630 & 0.000 \\
\hline \multicolumn{2}{|c|}{ Service Holder } & $17(45.9 \%)$ & $20(54.1)$ & & \\
\hline \multicolumn{2}{|c|}{ Business } & $14(100 \%)$ & $0(0 \%)$ & & \\
\hline \multicolumn{2}{|c|}{ Student } & $78(68.4 \%)$ & $36(31.6 \%)$ & & \\
\hline \multicolumn{6}{|c|}{ 5.Residence } \\
\hline \multicolumn{2}{|c|}{ Rural } & $80(94.1 \%)$ & $5(5.9 \%)$ & 21.505 & 0.000 \\
\hline \multicolumn{2}{|c|}{ Urban } & $125(68.3 \%)$ & $58(31.7 \%)$ & & \\
\hline \multicolumn{6}{|c|}{ 6.Family History of breast cancer } \\
\hline \multicolumn{2}{|c|}{ No } & $170(77.6 \%)$ & $49(22.4 \%)$ & 0.855 & 0.355 \\
\hline \multicolumn{2}{|c|}{ Yes } & $35(71.4 \%)$ & $14(28.6 \%)$ & & \\
\hline \multicolumn{6}{|c|}{$\begin{array}{l}\text { 7. Knowledge level regarding } \\
\text { breast cancer and BSE }\end{array}$} \\
\hline \multicolumn{2}{|c|}{ Good } & $46(42.5 \%)$ & $62(57.5 \%)$ & 115.660 & 0.000 \\
\hline \multicolumn{2}{|c|}{ Moderate } & $68(98.5 \%)$ & $1(1.5 \%)$ & & \\
\hline \multicolumn{2}{|c|}{ Poor } & $91(100 \%)$ & $0(0 \%)$ & & \\
\hline
\end{tabular}

Access to information: Two hundred and twentyeight people responded to the question regarding their breast cancer knowledge sources. Newspapers and social media provided the most information $(27.2 \%)$, followed by television and radio (26.3\%), family $(17.1 \%)$, friends/colleagues (14\%), health care personnel $(9.6 \%)$, and other $(5.7 \%)$ as shown in Figure 3.

Barriers to BSE practice: Two hundred five of the participants had never self-examined their breasts before $(76.49 \%)$. More than $80 \%$ of them cited "their ignorance of the BSE procedure" as the cause for their inability to do it. BSE was deemed unnecessary by $34 \%$ of those surveyed. It was deemed an "embarrassing event" by $24.39 \%$. BSE was avoided by $41 \%$ of people because they had no symptoms (Figure 4).

Confidence in the breast cancer treatment facilities: Only $11.2 \%$ of the respondents trusted the breast cancer treatment facilities of Bangladesh. More than half (59.3\%) expressed their dissatisfaction with the current facility, and $29.5 \%$ could not reach a firm conclusion (Figure 5). 


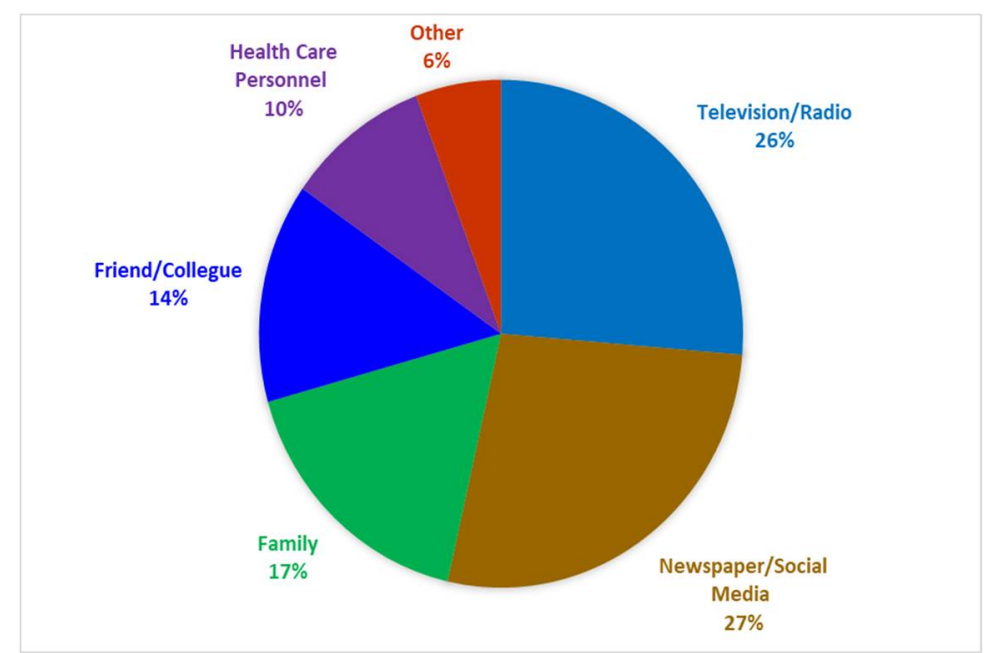

Figure 3. Sources of information of the participants about breast cancer and BSE.

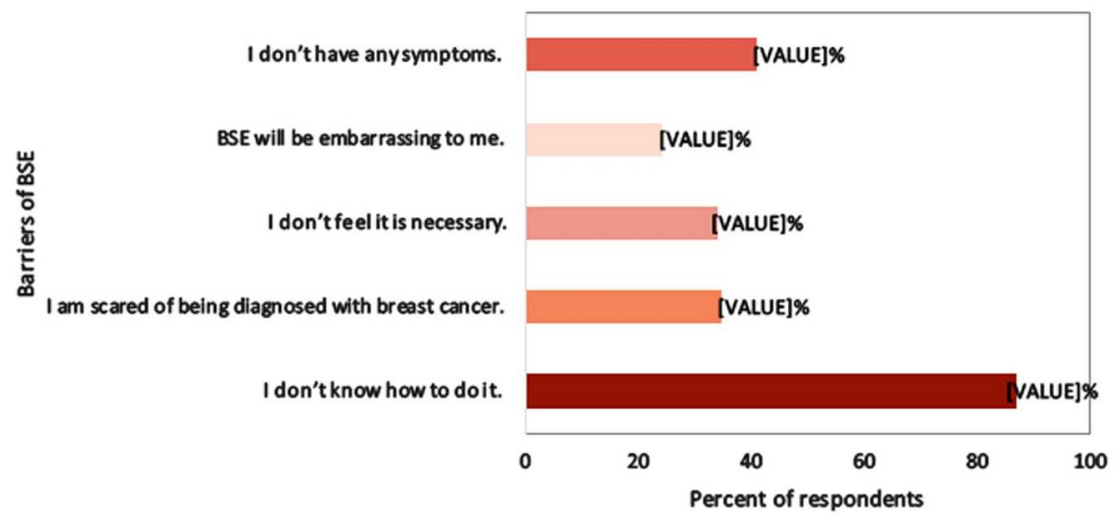

Figure 4. Barriers toward BSE practice.

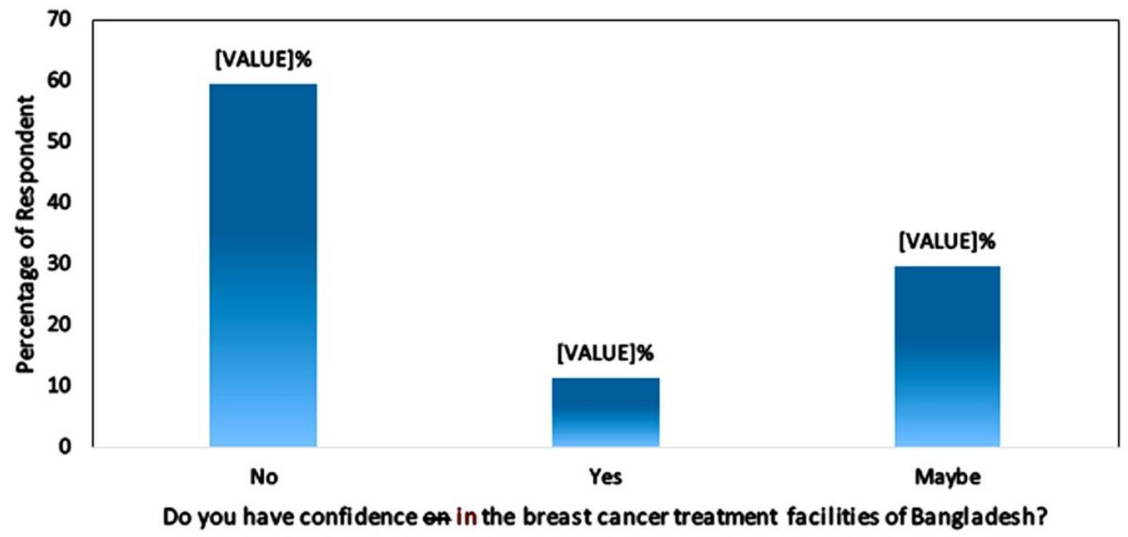

Figure 5. Confidence of the participants on breast cancer treatment facilities in Bangladesh. Table 6. Confidence in breast cancer treatment facilities in Bangladesh. 


\begin{tabular}{|c|c|c|c|c|}
\hline \multirow{2}{*}{\multicolumn{2}{|c|}{ Demographic factors }} & \multicolumn{3}{|c|}{$\begin{array}{l}\text { Do you have confidence in the treatment facilities of breast } \\
\text { cancer in Bangladesh? }\end{array}$} \\
\hline & & Yes $(\%)$ & No $(\%)$ & May be (\%) \\
\hline \multirow[t]{6}{*}{ 1.Age } & $15-30$ & & & \\
\hline & $30-40$ & $26(17.2 \%)$ & $73(48.3 \%)$ & $52(34.4 \%)$ \\
\hline & $40-50$ & $2(5.6 \%)$ & $26(72.2 \%)$ & $8(22.2 \%)$ \\
\hline & $50-60$ & $1(2.6 \%)$ & $30(78.9 \%)$ & $7(18.4 \%)$ \\
\hline & $>60$ & $1(2.6 \%)$ & $27(71.1 \%)$ & $10(26.3 \%)$ \\
\hline & & $0(0 \%)$ & $3(60.0 \%)$ & $2(40.0 \%)$ \\
\hline \multicolumn{5}{|c|}{ 2.Marital status } \\
\hline & Irried & $13(8.4 \%)$ & $103(66.9 \%)$ & $38(24.7 \%)$ \\
\hline & married & $17(14.9 \%)$ & $56(49.1 \%)$ & $41(36.0 \%)$ \\
\hline \multicolumn{5}{|c|}{ 3.Education Level } \\
\hline & educated & $1(3 \%)$ & $20(60.6 \%)$ & $12(36.4 \%)$ \\
\hline & hool & $3(3.9 \%)$ & $60(77.9 \%)$ & $14(18.2 \%)$ \\
\hline & llege & $4(8.5 \%)$ & $34(72.3 \%)$ & $9(19.1 \%)$ \\
\hline & iversity & $22(19.8 \%)$ & $45(40.5 \%)$ & $44(39.6 \%)$ \\
\hline \multicolumn{5}{|c|}{ 4.Occupation } \\
\hline & usewife & $3(2.9 \%)$ & $75(72.8 \%)$ & $25(24.3 \%)$ \\
\hline & vice Holder & $7(18.9 \%)$ & $19(51.4 \%)$ & $11(29.7 \%)$ \\
\hline & siness & $2(14.3 \%)$ & $8(57.1 \%)$ & $4(28.6 \%)$ \\
\hline & Ident & $18(15.8 \%)$ & $57(50.0 \%)$ & $39(34.2 \%)$ \\
\hline \multicolumn{5}{|c|}{ 5.Residence } \\
\hline & & $6(7.1 \%)$ & $46(54.1 \%)$ & $33(38.8 \%)$ \\
\hline & ban & $24(13.1 \%)$ & $113(61.7 \%)$ & $46(25.1 \%)$ \\
\hline \multicolumn{5}{|c|}{ 6.Family history of breast cancer } \\
\hline \multicolumn{5}{|c|}{ No } \\
\hline \multirow{2}{*}{\multicolumn{2}{|c|}{ Yes }} & $26(11.9 \%)$ & $118(53.9 \%)$ & $75(34.2 \%)$ \\
\hline & & $4(8.2 \%)$ & $41(83.7 \%)$ & $4(8.2 \%)$ \\
\hline
\end{tabular}



Figure 6. Preferred country of participants for breast cancer treatment. 
When asked which country they would prefer for cancer treatment, 182 respondents $(67.91 \%)$ picked a foreign country over Bangladesh. The majority of them (59.34\%) named India as their top option, followed by the United States (20.33\%), Singapore $(18.13 \%)$, the United Kingdom (7.7\%), and Thailand (3.85\%) as shown in Figure 06.

Knowledge on breast cancer: This project looked into Bangladeshi women's knowledge about breast cancer and their tendency to BSE practice. The majority of the participants in our survey had heard about breast cancer $(87.7 \%)$. This rate is higher than that observed in prior research among Bangladeshi women (Sultana et al., 2018). Furthermore, more than half of the participants are aware of BSE and breast cancer symptoms, which differs from the previous study in Bangladesh (Islam et al., 2016) but is comparable to that in Pakistan (Ahmed et al., 2018). Only $40 \%$ of the participants had an adequate understanding of breast cancer and BSE in general. Age, education, residence, and family history of breast cancer were modulatory factors in the knowledge level where elders, less educated, rural residents, and respondents with a negative family history of breast cancer were far behind in basic knowledge. The government can use our research findings to promote and sponsor awareness activities at regular intervals, particularly for marginalized communities.

Breast self-examination: The practice of BSE was not satisfactory among participants. Less than a third had done BSE before (23.5\%). A study conducted in Bangladesh in 2018 reported only $13.13 \%$ of the participants who performed BSE ever, which is much lower than our study (Sultana Tithi et al., 2018). In contrast, studies in Pakistan, Nigeria, and Ghana found a much higher rate, $33.1 \%, 43.2 \%$, and 37.6\%, respectively (Dadzi and Adam, 2019; Ahmed et al., 2018; Okobia et al., 2006). Only 5.2\% practiced BSE monthly, which is much lower than that of Malaysian study (28.5\%) (Al-Dubai et al., 2012). In terms of BSE practice, age, occupation, educational level, residence, and knowledge level on breast cancer demonstrated significant association with practice tendency. This finding is partially similar to that of Ghana and Malaysia, where the level of education and breast cancer knowledge level played a significant role in practicing behavior.

Access to information: Access to information is critical for growing awareness. Print and social media were the most often used sources of information in this survey's sample, followed by electronic media, which contradicts findings from a prior study in Saudi Arabia and Bangladesh, where electronic media was the most frequently used source of information (Alsowiyan et al., 2020). Another noteworthy finding is the absence of health care personnel as an information source. Only $9.2 \%$ of participants in our study obtained information from health care providers. Community-based health workers have made major improvements in Bangladesh's health care settings (El Arifeen et al., 2013), and this strategy can be used to offer necessary training and awareness materials on BSE practice to people' doorsteps once again.

Barriers to BSE: The current study revealed that a significant section of participants had never performed BSE, and the most common reason behind not performing it was "I don't know how to do it" $(86.83 \%)$. Another concerning reason behind this reluctance is the absence of any symptoms (40.97\%). This scenario vibrates with a study conducted in Malaysia, where almost $70 \%$ identified their ignorance about the procedure, and $64.7 \%$ declared absence of symptoms as a major factor (AkhtariZavare et al., 2015).

Confidence in the treatment facilities of breast cancer in Bangladesh: Only a small number of respondents in our study placed their trust in Bangladesh's breast cancer treatment settings. A review of the literature indicates inadequacies in our country's management of cancer patients. According to a survey performed in Bangladesh, the country has only 19 medical hospitals and institutes dedicated to cancer detection and treatment, far fewer than what is required. Additionally, the country's total cancer bed capacity is approximately 500 , which is insufficient 
to address the rising number of cancer cases. Furthermore, radiotherapy, a necessary component of cancer management, is offered in only 17 sites. Only one of these is located in a rural region (Hussain, 2013). These shortcomings in the health care system can prompt people to explore alternative options, such as medical travel to foreign countries. Our research revealed alarming findings: about $68 \%$ of respondents preferred medical care from a country other than Bangladesh, most noticeably India (59.34\%). This figure is comparable to that of a previous survey conducted in Bangladesh, in which $90 \%$ of individuals chose to seek medical care abroad (Kumar et al., 2021). Several factors may influence Bangladeshi patients' decision to travel to India for medical treatment, such as high-quality medical care, competent health care practitioners, affordable costs, and the unavailability of treatment options in Bangladesh.

Limitation of the study: Despite efforts to include people from various walks of life, the study sample may be skewed toward younger, more educated, and urban groups, resulting in conclusions that may differ from the actual scenario and do not necessarily represent the larger community. Furthermore, because the study is based on a self-administered questionnaire, it is impossible to ascertain whether participants were aware of the proper BSE method and breast cancer symptoms. Furthermore, because this study portrays BSE in a favorable light, responders may act in a more socially acceptable manner. Finally, advanced research is needed to find out the actual scenario of the understanding of breast cancer.

\section{Conclusion}

The study found a lack of overall understanding and BSE practice among Bangladesh's female population. Age, place of residence, educational level, and a family history of breast cancer all substantially impact knowledge level. This indicates the need for immediate intervention to promote awareness about breast cancer and BSE. Government and non-government organizations should regularly organize and sponsor-free health talks, workshops, and training programs on breast cancer. Health education programs should be promoted through various electronic, print, and social media platforms. Furthermore, the government should promptly strengthen the health sector by developing global standard diagnostic centers and hospitals capable of offering high-quality service at a fair cost.

\section{References}

Ahmed, A., Zahid, I., Ladiwala, Z. F. R., Sheikh, R. and Memon, A. S. 2018. Breast self-examination awareness and practices in young women in developing countries: A survey of female students in Karachi, Pakistan. J. Educ. Health Promot. 7, 90.

Akhtari-Zavare, M., Juni, M. H., Ismail, I. Z., Said, S. M. and Latiff, L. A. 2015. Barriers to breast self examination practice among Malaysian female students: a cross sectional study. SpringerPlus. 4, 1-6.

Al-Dubai, S. A. R., Ganasegeran, K., Alabsi, A. M., Manaf, M. R. A., Ijaz, S. and Kassim Saba, S. 2012. Exploration of barriers to breast-self examination among urban women in Shah Alam, Malaysia: a cross sectional study. Asian Pac. J. Cancer Prev, 13, $1627-$ 1632.

Alsowiyan, A. A., Almotyri, H. M., Alolayan, N. S., Alissa, L. I., Almotyri, B. H. and AlSaigh, S. H. 2020. Breast cancer knowledge and awareness among females in Al-Qassim Region, Saudi Arabia in 2018. J. Family Med. Prim. Care, 9, 1712-1718.

Dadzi, R. and Adam, A. 2019. Assessment of knowledge and practice of breast self-examination among reproductive age women in Akatsi South district of Volta region of Ghana. PLOS ONE, 14, e0226925.

El Arifeen, S., Christou, A., Reichenbach, L., Osman, F. A., Azad, K., Islam, K. S., Ahmed, F., Perry, H. B. and Peters, D. H. 2013. Community-based approaches and partnerships: innovations in health-service delivery in Bangladesh. Lancet, 382, 2012-2026.

Hussain, S. M. A. 2013. Comprehensive update on cancer scenario of Bangladesh. South Asian J. Cancer, 2, 279.-284.

Islam, R.M., Bell, R.J., Billah, B., Hossain, M.B. and Davis, S.R. 2016. Awareness of breast cancer and barriers to breast screening uptake in Bangladesh: A population based survey. Maturitas, 84, 68-74.

Kumar, D., Bagchi, S. and Ray, S. 2021. Why Bangladeshi patients prefer outbound medical travel? an analytical study. ITHJ, 4, 1-15. 
Lam, W. W. M., Chan, C. P., Chan, C. F., Mak, C. C. C., Chan, C. F., Chong, K. W. H., Leung, M. H. J., and Tang, M. H. 2008. Factors affecting the palpability of breast lesion by self-examination. Singapore Med. J. 49, 228-232.

Lu, W. L., Jansen, L., Post, W. J., Bonnema, J., Van de Velde, J. C. and De Bock, G. H.2008. Impact on survival of early detection of isolated breast recurrences after the primary treatment for breast cancer: a meta-analysis. Breast Cancer Res. Treat. 114, 403-412.

Oeffinger, K. C., Fontham, E. T. H., Etzioni, R., Herzig, A., Michaelson, J. S., Shih, Y. C. T., Walter, L. C., Church, T. R., Flowers, C. R., LaMonte, S. J., Wolf, A. M. D., DeSantis, C., Lortet-Tieulent, J., Andrews, K., Manassaram-Baptiste, D., Saslow, D., Smith, R. A., Brawley, O. W. and Wender, R. 2015. Breast cancer screening for women at average risk: 2015

guideline update from the American Cancer Society. JAMA, 314, 1599-1614. Okobia, M. N., Bunker, C. H., Okonofua, F. E. and Osime, U. 2006. Knowledge, attitude and practice of Nigerian women towards breast cancer: A cross-sectional study. World J. Surg. Oncol. 4, 1-9.
Rosenberg, R. D., Hunt, W. C., Williamson, M. R., Gilliland, F. D., Wiest, P. W., Kelsey, C. A., Key, C. R. and Linver, M. N. 1998. Effects of age, breast density, ethnicity, and estrogenreplacement therapy on screening mammographic sensitivity and cancer stage at diagnosis:

Review of 183,134 screening mammograms in Albuquerque, New Mexico. Radiology, 209, 511-518.

Sultana, T. N., Asaduzzaman, M., Nasrin, N., Monjur, H. M., Rahman, N., Akter, N. N. and Syeed, N. 2018. A cross-sectional survey on knowledge regarding breast cancer and breast self-examination among Bangladeshi women. IOSR-JPBS, 13, 38-44.

Sung, H., Ferlay, J., Siegel, R. L., Laversanne, M., Soerjomataram, I., Jemal, A. and Bray, F. 2021. Global cancer statistics 2020: GLOBOCAN estimates of incidence and mortality worldwide for 36 cancers in 185 countries. CA Cancer J. Clin. 71, 209-249.

Torre, L. A., Bray, F., Siegel, R. L., Ferlay, J., LortetTieulent, J. and Jemal, A. 2015. Global cancer statistics, 2012. CA Cancer J. Clin. 65, 87-108.

Unger-Saldaña, K. 2014. Challenges to the early diagnosis and treatment of breast cancer in developing countries. World J. Clin. Oncol. 5, 465-477.

Yalaza, M., İnan, A. and Bozer, M. 2016. Male breast cancer. J. Breast Health, 12, 1-8. 